\title{
Unilateral lung transplantation using intact bilateral upper lobes
}

Shinji Otani, MD, Takeshi Kurosaki, MD, Seiichiro Sugimoto, MD, Masaomi Yamane, MD, and

Takahiro Oto, MD, Okayama, Japan

From the Department of Thoracic Surgery/Organ Transplant Center, Okayama University Hospital, Okayama, Japan.

This study was supported in part by a grant from the Ministry of Health, Labor, and Welfare, Japan and the Japan Society for the Grants-in-Aid for Scientific Research \#16K1998008 (to S.O.)

Disclosures: Authors have nothing to disclose with regard to commercial support.

Received for publication Nov 27, 2017; revisions received Feb 28, 2018; accepted for publication March 3, 2018; available ahead of print March 30, 2018.

Address for reprints: Takahiro Oto, MD, Department of Thoracic Surgery/Organ Transplant Center, Okayama

University Hospital, 2-5-1 Shikata, Kita-ku, Okayama 700-8558, Japan (E-mail: oto@md.okayama-u.ac.jp).

J Thorac Cardiovasc Surg 2018;156:e35-8

$0022-5223 / \$ 36.00$

Copyright (C) 2018 by The American Association for Thoracic Surgery

https://doi.org/10.1016/j.jtcvs.2018.03.003

Extended-criteria donor lungs have come to be used for transplantation more frequently worldwide. In marginal grafts, both lower lobes are often collapsed or infected, whereas both the upper lobes might still be usable for transplantation. In these cases, when the recipient is considered as high risk or when the damage of lower lobes is judged to

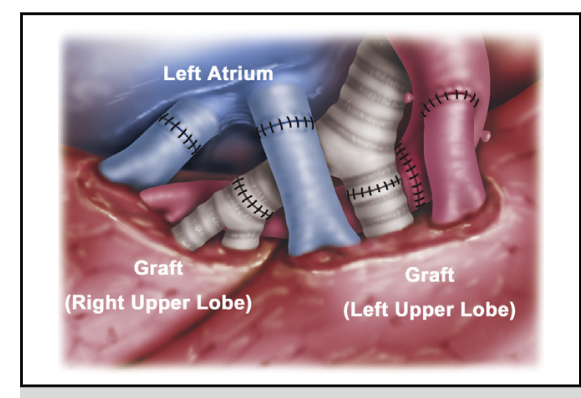

Schema of anastomoses of this unilateral LTX using upper-lobe grafts.

\section{Central Message}

Unilateral LTx using intact bilateral upper lobes can broaden the donor pool by increasing the chance for high-risk recipients when using marginal lung grafts with damaged lower lobes.

See Editorial Commentary page e39.

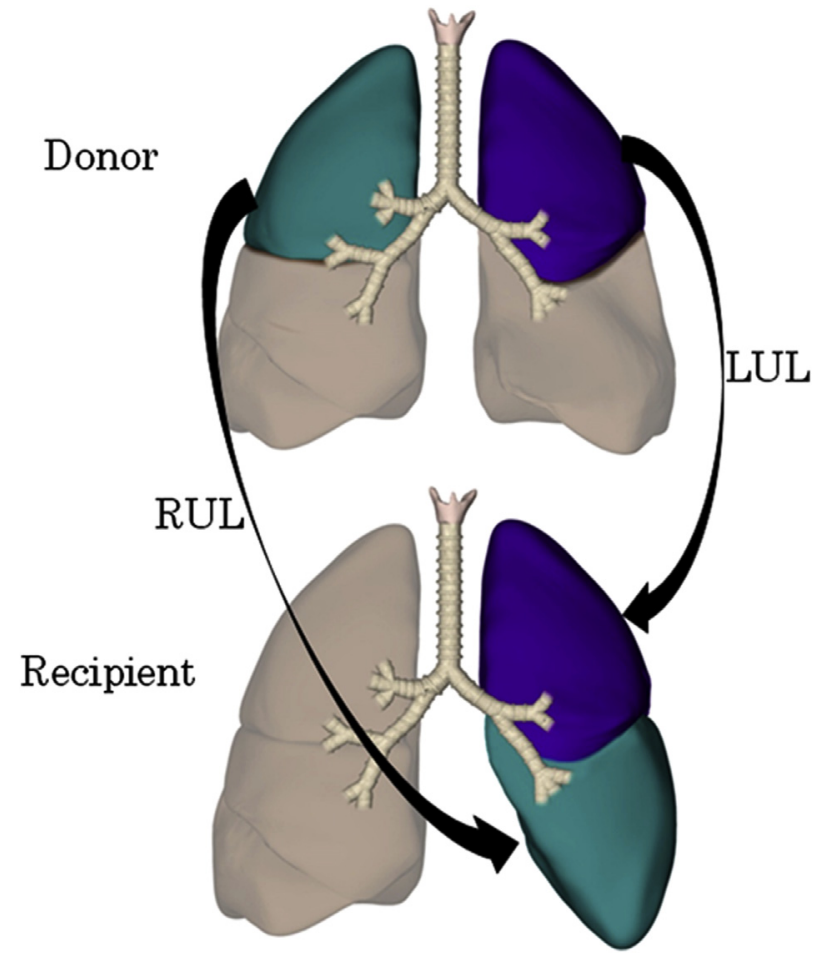

FIGURE 1. Schema of this operation. $L U L$, Left upper lobe; $R U L$, right upper lobe. Reprinted with permission. be irreversible, all lobes, including the healthy upper lobes, would be rejected at a not negligible frequency. Previously, we reported the feasibility of using bilateral lobes for unilateral lung transplantation (LTx) in a swine experiment ${ }^{1}$ (Figure 1). We present a successful unilateral cadaveric LTx in a high-risk recipient using intact upper lobes from marginal grafts (Figure 2). To the best of our knowledge, this is the first report of the unilateral LTx using bilateral upper-lobe grafts.

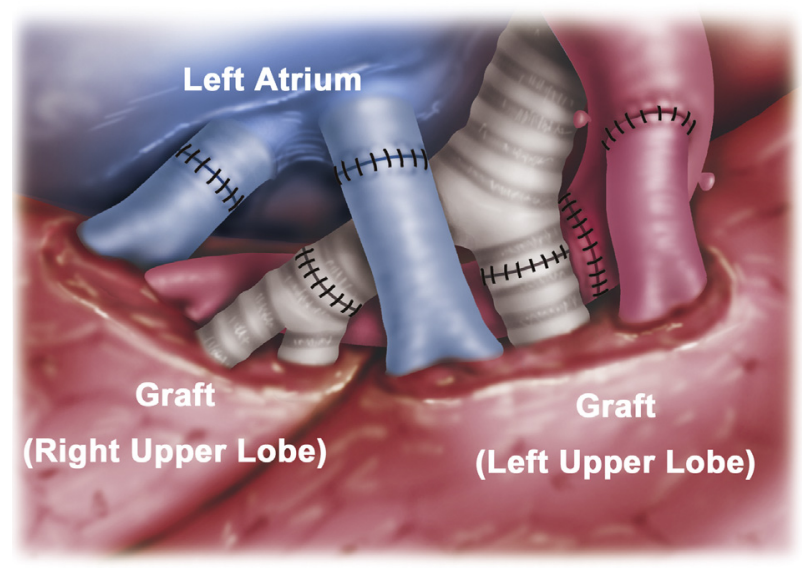

FIGURE 2. Schema of the anastomoses. 


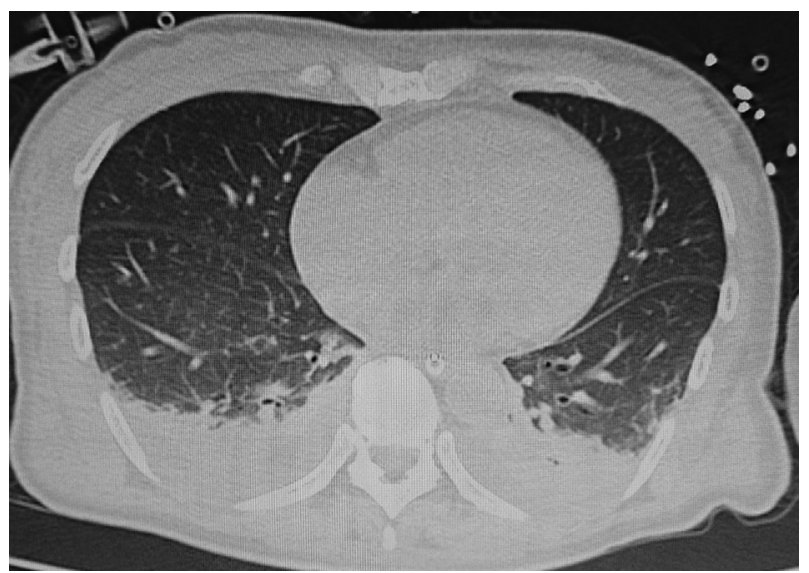

FIGURE 3. Computed tomography image of the donor lung demonstrates infiltration in the bilateral lower lobes.

\section{CLINICAL SUMMARY}

A woman with emphysema underwent cadaveric right single LTx, and 32 months later, she required noninvasive positive-pressure ventilation on bed rest and was relisted for LTx. At 54 years old, she had the opportunity to receive a lung graft that was rejected by all other lung transplant centers in Japan.

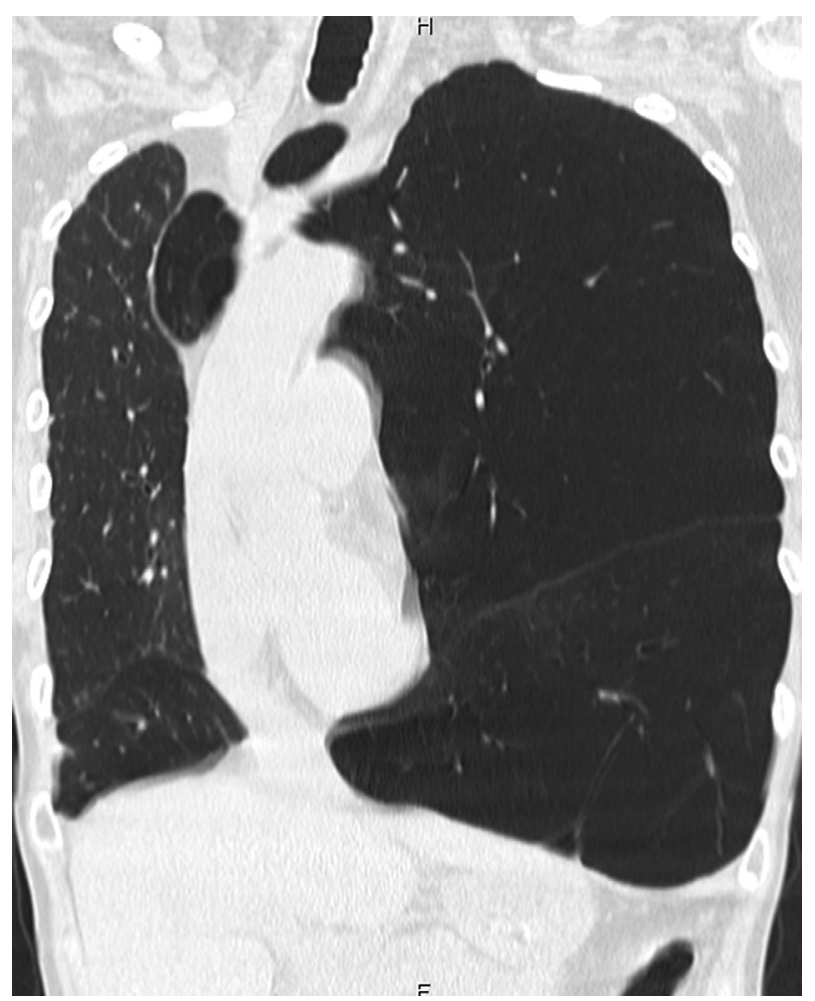

FIGURE 4. Preoperative computed tomography image of the recipient's native left lung shows severe emphysematous change, compressing her mediastinum to the right.

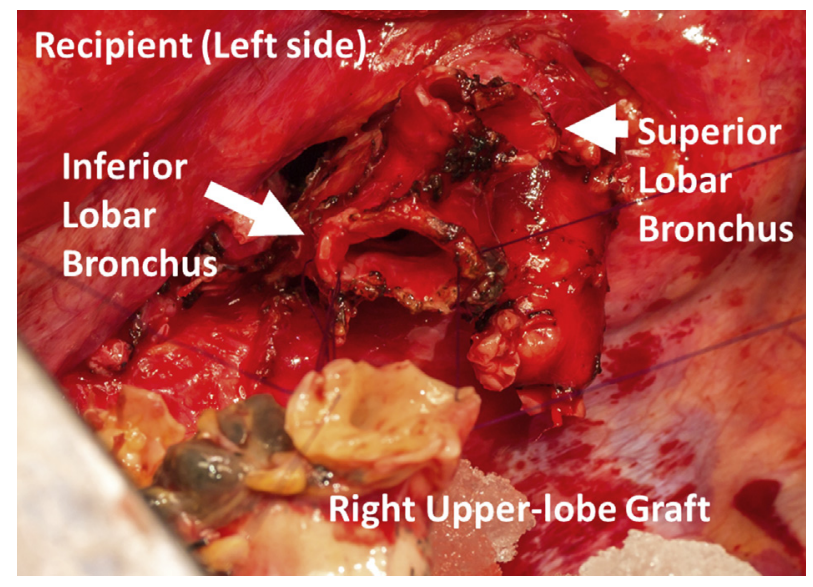

FIGURE 5. Before bronchial anastomosis of the right upper-lobe graft.

The lung graft from the seawater-drowned donor was marginal. Chest images of the donor lungs, despite partial pressure of arterial oxygen/fraction of inspired oxygen ratio 417 , showed infiltration in the bilateral lower lobes, indicating a possible infection 10 days after intubation (Figure 3). The recipient seemed to be sick enough to not survive until the next chance of a transplantation and was at higher risk when using marginal lungs. The recipient's native left lung with severe emphysema, which had compressed her mediastinum to the right, seemed to be the main reason for the recipient's poor pulmonary function, and bronchiolitis obliterans syndrome of the recipient's right lung was mild (Figure 4). We decided to perform a left unilateral LTx using bilateral upper-lobe grafts.

At the back table, each upper-lobe graft was prepared for reconstruction. The edge of the bronchus was cut to avoid leaving bronchial stumps and trimmed into a trumpet shape to fit the recipient's larger bronchus. The main pulmonary

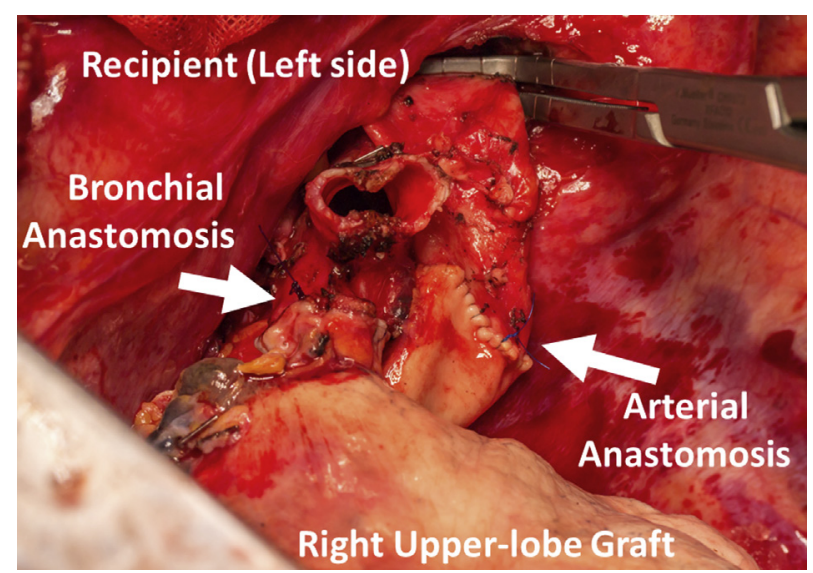

FIGURE 6. After arterial anastomosis of the right upper-lobe graft. 


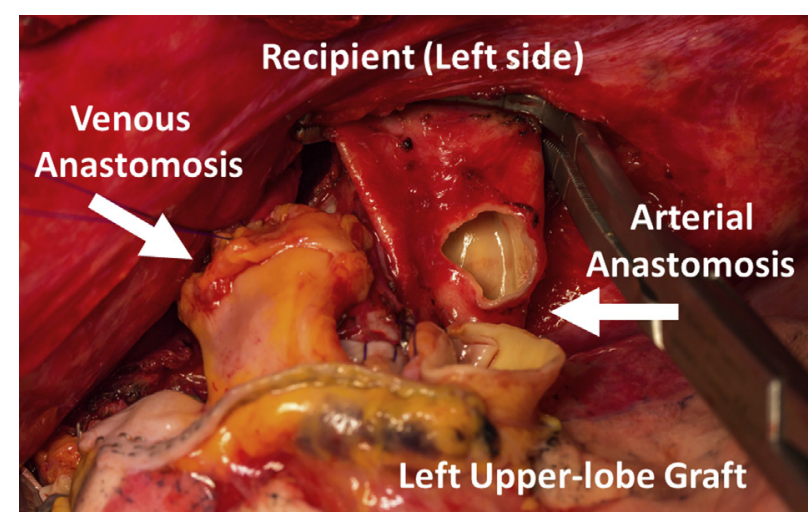

FIGURE 7. Before arterial anastomosis of the left upper-lobe graft.

artery was well preserved with the peripheral end ligated. The right middle lobar vein was ligated and cut.

The right upper-lobe graft was implanted as the recipient's left lower lobe with cardiopulmonary bypass by central cannulation through a semi-clamshell incision with an additional 4-cm incision to the right and sternal transection. First, bronchus of the right upper-lobe graft was rotated $90^{\circ}$ clockwise and anastomosed to the recipient's left inferior lobar bronchus (Figure 5). The graft's middle-lobe side was fixed toward the mediastinal side. The right main pulmonary artery of the right upper-lobe graft was anastomosed to the recipient's preserved artery at the level of the A6 branch in an end-to-end fashion behind the last bronchial anastomosis (Figure 6). Venous anastomosis was performed between the graft's right superior pulmonary vein and the recipient's left inferior pulmonary vein at the front of the bronchial anastomosis. The left upper-lobe graft was implanted in the usual manner, except the arterial anastomosis was performed in an end-to-side fashion, which was made between the graft's main pulmonary artery and the punched-out hole of the recipient's pulmonary artery at the level of the first branch (Figure 7). The total operating time was 553 minutes, and the graft ischemic time was 674 minutes.

The bilobar graft fit into a good position without torsion of the bronchi and vessels (Figure 8). The patient experienced no severe primary graft dysfunction or any complications.

\section{DISCUSSION}

Recipient-donor matching is the key to maintain healthy post-transplant survival outcomes, and many lung transplant centers avoid marginal grafts in high-risk recipients. ${ }^{2,3}$ Generally, unilateral LTx is less invasive than bilateral LTx, especially in the acute postoperative period. Therefore, unilateral LTx using only intact lobes can be a reasonable option for a high-risk recipient. However, this complicated operation has potential risks: kinking of the vascular anastomosis, complications related to the bronchial anastomosis, and atelectasis due to imperfect fit of the lobes in the recipient's chest cavity. Although this recipient experienced no airway complication, suggesting feasibility of lobar-to-lobar transplantation without bronchial stumps, risk and benefit should be carefully considered.

LTx from seawater-drowned donors with possible aspiration is thought to be controversial. The short- and long-term outcomes of using lungs from drowned donors are reportedly feasible for transplantation. ${ }^{4,5}$ Given that this recipient had enough reserve, the bilateral lower-lobe graft, which was damaged by seawater, might have been reversible within a few days.

\section{CONCLUSIONS}

Unilateral LTx using bilateral upper lobes is a feasible and reasonable option for a high-risk recipient when using marginal lung grafts with intact bilateral upper lobes.
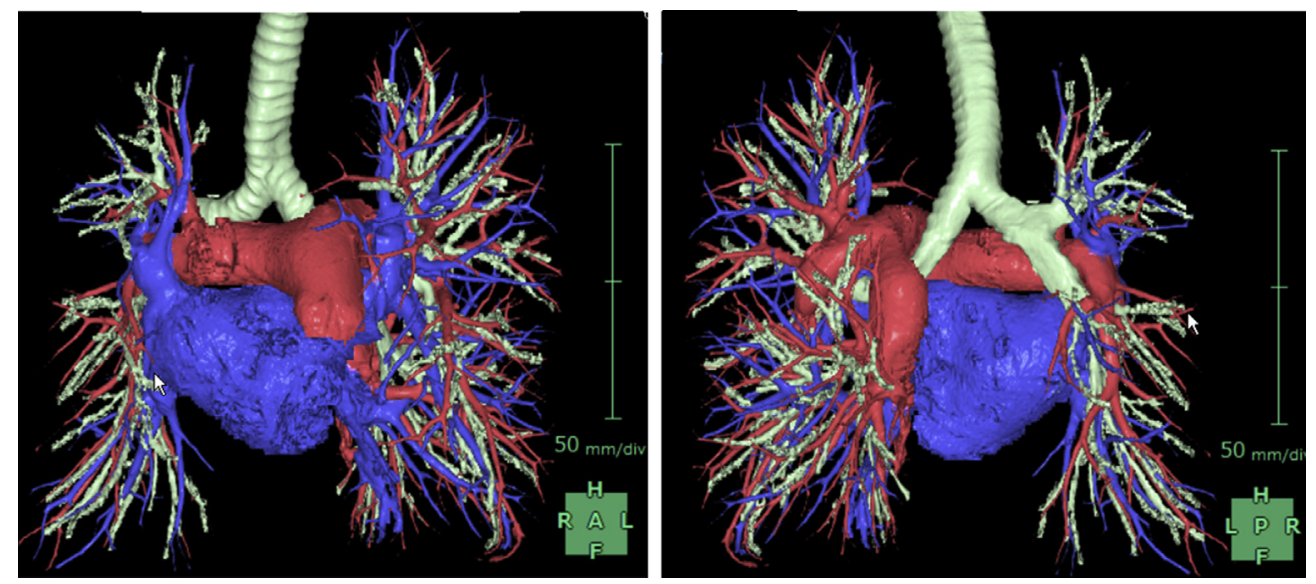

FIGURE 8. Postoperative 3-dimensional computed tomography images of the recipient. $H$, Head; $R$, right; $A$, anterior; $L$, left; $F$, foot; $P$, posterior. 


\section{References}

1. Nishikawa H, Oto T, Otani S, Harada M, Iga N, Miyoshi K, et al. Unilateral lung transplantation using right and left upper lobes: an experimental study. J Thorac Cardiovasc Surg. 2013;146:1534-7.

2. Moreno P, Alvarez A, Santos F, Vaquero JM, Baamonde C, Redel J, et al Extended recipients but not extended donors are associated with poor outcomes following lung transplantation. Eur J Cardiothorac Surg. 2014;45 1040-7.
3. Mulligan MJ, Sanchez PG, Evans CF, Wang Y, Kon ZN, Rajagopal K, et al. The use of extended criteria donors decreases one-year survival in high-risk lung recipients: a review of the united network of organ sharing database. J Thorac Cardiovasc Surg. 2016;152:891-8.e892.

4. Hoetzenecker K, Ankersmit HJ, Lang G, Scheed A, Marta G, Jaksch P, et al. Considerations on infectious complications using a drowned lung for transplantation. Transpl Int. 2010;23:e32-4.

5. McNamee CJ, Modry DL, Lien D, Conlan AA. Drowned donor lung for bilateral lung transplantation. J Thorac Cardiovasc Surg. 2003;126:910-2. 